\title{
School air quality related to dry cough, rhinitis and nasal patency in children
}

\author{
M. Simoni*, I. Annesi-Maesano\#, T. Sigsgaard", D. Norback, G. Wieslander ${ }^{+}$, \\ W. Nystad ${ }^{\S}$, M. Canciani ${ }^{f}$, P. Sestini* and G. Viegi* ${ }^{\star \# \#}$
}

ABSTRACT: Controls for indoor air quality (IAQ) in schools are not usually performed throughout Europe. The aim of this study was to assess the effects of IAQ on respiratory health of schoolchildren living in Norway, Sweden, Denmark, France and Italy.

In the cross-sectional European Union-funded HESE (Health Effects of School Environment) Study, particulate matter with a $50 \%$ cut-off aerodynamic diameter of $10 \mu \mathrm{m}\left(\mathrm{PM}_{10}\right)$ and $\mathrm{CO}_{2}$ levels in a day of normal activity (full classroom) were related to wheezing, dry cough at night and rhinitis in 654 children (10 yrs) and to acoustic rhinometry in 193 children.

Schoolchildren exposed to $\mathrm{PM} 10>50 \mu \mathrm{g} \cdot \mathrm{m}^{-3}$ and $\mathrm{CO}_{2}>1,000 \mathrm{ppm}$ (standards for good IAQ) were $78 \%$ and $66 \%$, respectively. All disorders were more prevalent in children from poorly ventilated classrooms. Schoolchildren exposed to $\mathrm{CO}_{2}$ levels $>1,000 \mathrm{ppm}$ showed a significantly higher risk for dry cough (OR 2.99, 95\% Cl 1.65-5.44) and rhinitis (OR 2.07, 95\% Cl 1.14-3.73). By two-level (child, classroom) hierarchical analyses, $\mathrm{CO}_{2}$ was significantly associated with dry cough (OR 1.06, 95\% Cl 1.00-1.13 per 100 ppm increment) and rhinitis (OR 1.06, 95\% $\mathrm{Cl} 1.00-$ 1.11). Nasal patency was significantly lower in schoolchildren exposed to $P M 10>50 \mu \mathrm{g} \cdot \mathrm{m}^{-3}$ than in those exposed to lower levels.

A poor IAQ is frequent in European classrooms; it is related to respiratory disturbances and affects nasal patency.

KEYWORDS: Carbon dioxide, indoor air pollution, particles, respiratory, rhinometry, schoolchildren

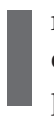

ndoor environments contribute to human exposure to pollutants [1]. Levels of some pollutants can be several folds higher indoors than outdoors; even low concentrations of indoor pollutants may have adverse biological effects when exposures are prolonged.

Several reports underline the role of indoor pollution in affecting respiratory health in both children and adults [2-7]. Since children spend a large part of their time at school, nationwide initiatives to evaluate such indoor air quality (IAQ) were developed in the USA [8].

Respiratory/allergic disorders are common throughout Europe and represent a substantial burden of health service cost. Studies of school environment and related health effects in children have been performed in Europe, especially in northern countries, although mostly on small samples [9-13]. A European Union (EU)-funded project developed by the European Federation of Asthma and Allergy Associations [14] found the right of breathing clean air at school was not widely respected throughout Europe. The
European Commission, through the Directorate General for Health and Consumer Affairs (DG SANCO, Luxembourg, Luxembourg), funded our study on Health Effects of School Environment (HESE) held in different European countries; we report the results here.

\section{METHODS}

The cross-sectional HESE study involved six operational units in five European countries (Siena and Udine, Italy; Reims, France; Oslo, Norway; Uppsala, Sweden; and Århus, Denmark). 21 schools (46 classrooms) with heterogeneous characteristics were selected, including a broad age range of buildings and a variety of location characteristics (about half in environmentally more advantaged areas and half in less advantaged areas). The study, approved by the ethics committees of each study centre, was carried out in 2004-2005, during the heating season, and lasted a full week in each location.

The study protocol included: 1) one standardised questionnaire on school characteristics and IAQ policy completed by the teachers; 2) two
AFFILIATIONS

*Pulmonary Environmental

Epidemiology Unit, CNR Institute of

Clinical Physiology, Pisa,

fUdine University-Hospital

"Policlinico", Udine,

** Siena University, Institute of

Respiratory Diseases, Siena,

\#\# CNR Institute of Biomedicine and

Molecular Immunology "A. Monroy",

Palermo, Italy.

\#UMR-S 707, Medical School

St-Antoine, University Pierre et Marie

Curie and INSERM, Paris, France.

-IMA Institute of Environment and

Occupational Medicine, Århus

University, Århus, Denmark.

+Uppsala University, Dept of Medical

Sciences, Uppsala, Sweden.

${ }^{\S}$ Norwegian Institute of Public Health,

Division of Epidemiology, Oslo,

Norway.

CORRESPONDENCE

M. Simoni

Istituto di Fisiologia Clinica CNR

(CNR Institute of Clinical Physiology)

Via Trieste, 41

56126 Pisa

Italy

E-mail: marzia_simoni@libero.it

Received:

Jan 302009

Accepted after revision:

Nov 042009

First published online:

Jan 142010

European Respiratory Journal

Print ISSN 0903-1936

Online ISSN 1399-3003 
standardised questionnaires derived from the International Study of Asthma and Allergies in Childhood (ISAAC) questionnaire on characteristics of children (i.e. health conditions, lifestyle, home environment), one filled in by the pupils and the other by their parents; 3) school environmental assessments; and 4) noninvasive clinical tests on a subsample of pupils.

\section{Symptoms/diseases}

The standardised questionnaires were filled in by 547 pupils and 552 parents (response rate $84 \%$ for both). In Denmark, only parents' questionnaires were available. Among children with both self- and parental report ( $n=445,68 \%$ of total), symptoms / diseases were considered as present when either children or parents reported any symptom/disease and absent when both children and parents did not report any symptom/disease. In order to retain the highest number of children and countries in the analyses, data on children with only self-report $(n=107$, $16.4 \%)$ or only parental report $(n=102,15.6 \%)$ were also included in the data set. Thus, health status was derived for 654 children (47.2\% young males, mean \pm SD age $10 \pm 0.8 \mathrm{yrs})$.

The following recent symptoms/diseases were considered in the analyses: 1) wheeze ("have you had, or has your child had, wheezing or whistling in the chest in the past 12 months?"); 2) dry cough at night ("in the past 12 months, have you had, or has your child had, a dry cough at night, apart from a cough associated with a cold or chest infection?"); 3 ) rhinitis ("in the past 12 months, have you had, or has your child had, a problem with sneezing, or a runny or blocked nose when you did not have a cold or the flu?'”).

\section{Environmental measurements}

During normal activities (full classroom), standard measurements (ventilation, temperature, relative humidity, lighting, particles, nitrogen dioxide, carbon dioxide, ozone, formaldehyde, dust and air allergens, moulds and bacteria) were performed, both inside and outside each school, by personnel from a single centre, where the instruments had been calibrated (Uppsala). Data were analysed at the IVL Swedish Environmental Research Institute in Gothenburg, Sweden and at the Department of Occupational and Environmental Medicine, Orebro, Sweden.

Carbon dioxide (ppm) was measured by a $\mathrm{Q}$-Trackt ${ }^{\mathrm{TM}}$ IAQ Monitor (TSI Incorporated, St Paul, MN, USA), a direct reading instrument with an in-built data logger, by sampling 1-min average intervals at $0.9 \mathrm{~m}$ above the floor during 1 day (minimum $4 \mathrm{~h}$ ).

Respirable particulate matter with aerodynamic diameter $<10 \mu \mathrm{m}$ (PM10; $\mu \mathrm{g} \cdot \mathrm{m}^{-3}$ ) was measured by a Dust-Trackt ${ }^{\mathrm{TM}}$ (Model 8520; TSI Incorporated) with a sensor-type $90^{\circ}$ lightscattering laser photometer, measuring 1-10 $\mu \mathrm{m}$ particles for $1-2 \mathrm{~h}$.

Personal outdoor air supply rate $(\mathrm{A}=$ ventilation rate, $\mathrm{L} \cdot \mathrm{s}^{-1} \cdot$ person $^{-1}$ ) was computed from the graphically estimated equilibrium of $\mathrm{CO}_{2}$ concentration, as follows:

$$
\mathrm{A}=\mathrm{P} /\left(\mathrm{C}_{\text {mean }}-\mathrm{C}_{\mathrm{O}}\right) \times 10^{6} / 3,600
$$

where $\mathrm{P}$ is the personal emission rate of $\mathrm{CO}_{2}$ in $\mathrm{L} \cdot \mathrm{s}^{-1}$ for sedentary office work at sea level $\left(18 \mathrm{~L} \cdot \mathrm{h}^{-1}\right)$, and $\mathrm{C}_{\text {mean }}$ and $\mathrm{C}_{\mathrm{O}}$ are the mean $\mathrm{CO}_{2}$ levels in the classroom and outdoor, respectively [15].

\section{Clinical tests}

Noninvasive clinical tests (skin-prick tests, spirometry, acoustic rhinometry, exhaled nitrogen oxide, collection of breath condensate and nasal secretions, break-up time and tear film analysis) were performed on five randomised selected pupils in each class.

For the current analyses, we focused on the results by acoustic rhinometry, because we considered upper respiratory tract disorders, and because the relationship between school environment and nasal patency (the degree of openness of the nose) of schoolchildren has never been investigated. Acoustic rhinometry precisely locates the nasal minimum cross-sectional area (MCA) of each nostril by analysis of sound reflection from the nasal cavity. Acoustic rhinometry was not performed in Norway. Except for Denmark, the same equipment (Rhin 2000; SR Electronics, Denmark; wideband noise, continuously transmitted) was used. The continuous sound measurement makes it very easy to hear if the nose adapter does not tightly fit the nose. In Denmark, the measurements were performed with a rhinometer using a single-spark signal (GJ Electronic, Skanderborg, Denmark). At start-up, both sets of equipment were calibrated using a tube with the same fixed length and volume changes in order to obtain standardised measurements. Measurements were performed by experienced medical staff while the child was sitting, after $\geqslant 5$ min of rest; usually, because of queuing, the rest time was much longer. All schoolchildren waited in their classrooms for $\geqslant 1 \mathrm{~h}$ before the investigation. MCAs for each nostril were measured at a distance of 0-22 mm (anterior MCA) and 23-54 mm (posterior MCA) from the nasal opening [16]. Mean values were calculated from three subsequent measurements on each side of the nose, and presented data are the sum of the values recorded for the right side and the left side of the nose. The anterior MCA was measured in 193 children. The posterior MCA was measured in 140 children (in Denmark, only the anterior MCA was measured).

\section{Statistical analyses}

Statistical analyses were performed with SPSS version 13.0 (SPSS, Chicago, IL, USA) and STATA version 9.0 (STATA, College Station, TX, USA). Levels of PM10 $>50 \mu \mathrm{g} \cdot \mathrm{m}^{-3}$ (US Environmental Protection Agency (EPA) standard for longterm exposure) [17] and $\mathrm{CO}_{2}>1,000 \mathrm{ppm}$ (American Society of Heating, Refrigerating and Air-Conditioning Engineers (ASHRAE) standard) [18] were defined as elevated. A categorical variable of exposure was defined for both pollutants (elevated versus low).

Levels of personal outdoor air supply $<8 \mathrm{~L} \cdot \mathrm{s}^{-1} \cdot$ person $^{-1}$ indicated insufficient ventilation, as suggested by ASHRAE [19]. To assess the relationship between ventilation and respiratory health, we used a cut-off of $10 \mathrm{~L} \cdot \mathrm{s}^{-1} \cdot$ person $^{-1}$ [20].

The following SPSS routines were applied: frequency distributions, analyses of correlation, ANOVA, Chi-squared test, Kruskall-Wallis nonparametric test, multiple linear regression and logistic regression models with each disorder as the dependent variable. $\mathrm{CO}_{2}$ and PM10 were entered in the models 


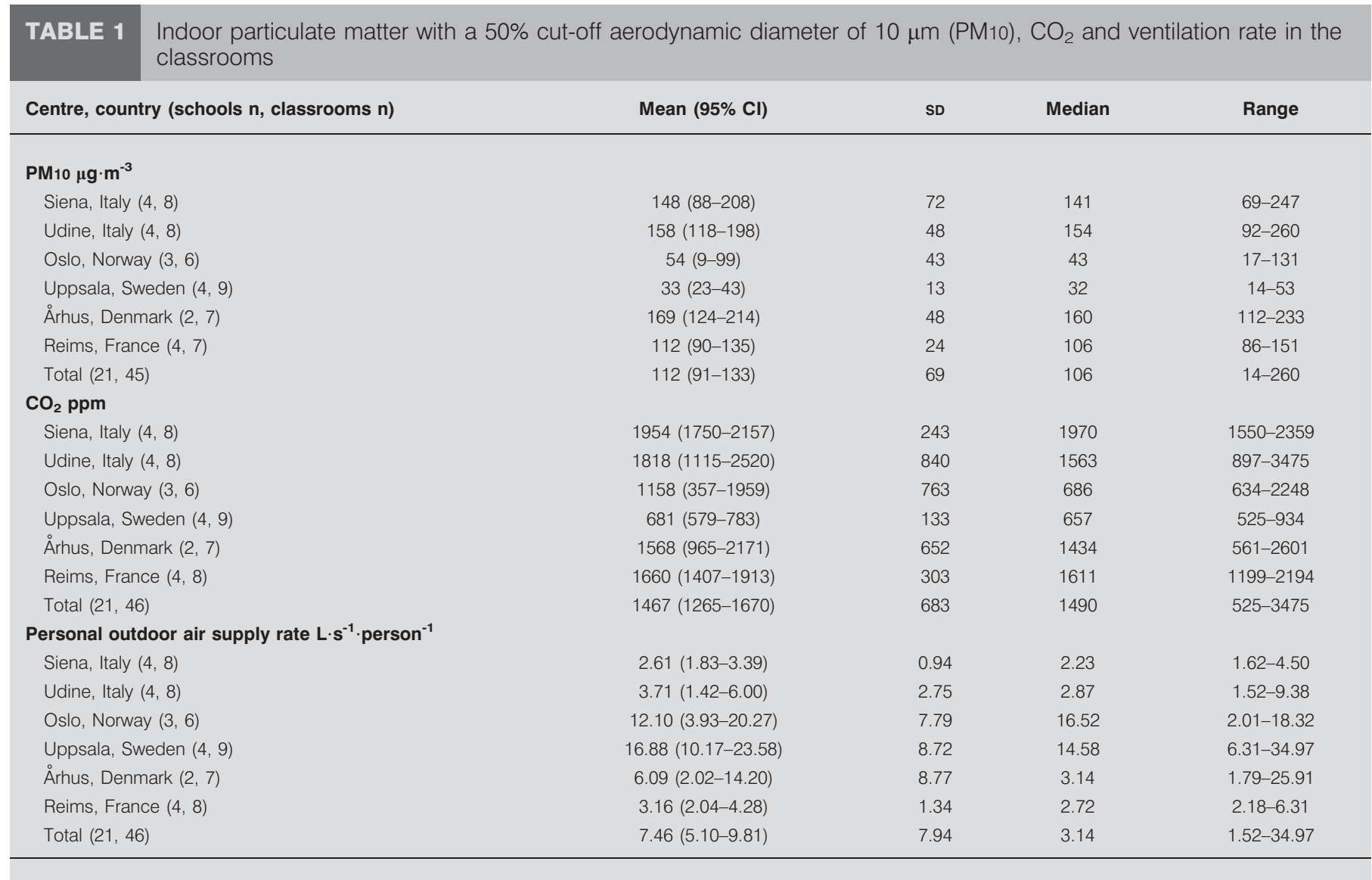

either as binary exposure variables (elevated versus low) or as continuous variables (PM10: $10 \mu \mathrm{g} \cdot \mathrm{m}^{-3}$ increments; $\mathrm{CO}_{2}$ : $100 \mathrm{ppm}$ increments). Besides conventional logistic regression, we fitted random intercept two-level models for binary dependent variables using the STATA gllamm (generalised linear latent and mixed models) command with logit link function, which estimates the maximum likelihood (numerical integration to evaluate the marginal log-likelihood and numerical derivatives to maximise it). Two hierarchical levels were considered: first level, the child; second level, the classroom.

\section{RESULTS}

\section{School environment}

In most centres, the indoor mean concentration of PM10 exceeded the $50 \mu \mathrm{g} \cdot \mathrm{m}^{-3}$ cut-off suggested by the EPA for long-term exposures (table 1): lower or slightly higher mean levels only occurred in Uppsala and Oslo. Elevated mean concentrations were mainly in Danish and Italian schools. A level $>50 \mu \mathrm{g} \cdot \mathrm{m}^{-3}$ was found in $77.8 \%$ of the classrooms, and a level $>150 \mu \mathrm{g} \cdot \mathrm{m}^{-3}$ (EPA standard for 24-h exposure) was found in Italy and Denmark (fig. 1). PM10 levels were always higher inside than outside the school (outdoor mean $63.6 \mu \mathrm{g} \cdot \mathrm{m}^{-3}$, range 6-302), with a mean indoor/outdoor ratio of 3.4 (range 0.5-38.7).

Indoor $\mathrm{CO}_{2}$ was correlated to indoor PM10 (Pearson $\mathrm{r}=0.64$, $\mathrm{p}<0.001$ ), but the relationship was only moderately linear ( $\sim 40 \%$ of the variation of $\mathrm{CO}_{2}$ explains the variation of PM10).
Mean concentrations exceeded 1,000 ppm in all schools, except for Sweden (table 1), and in $66 \%$ of the classrooms (fig. 2). The highest values were measured in Italy, followed by France and Denmark. Mean outdoor $\mathrm{CO}_{2}$ was 398 ppm, and mean indoor/ outdoor ratio was 3.7 (range 1.3-9.1).

The mean personal outdoor air supply rate in the total sample was $7.64 \mathrm{~L} \cdot \mathrm{s}^{-1} \cdot$ person $^{-1}$. The lowest values were found in Italy and France, whereas the highest was in Sweden (table 1).

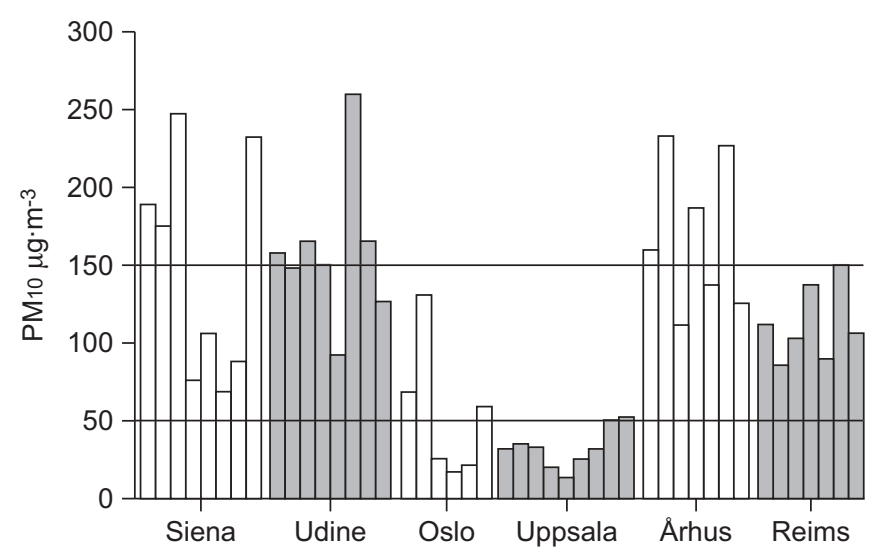

FIGURE 1. Indoor particulate matter with a $50 \%$ cut-off aerodynamic diameter of $10 \mu \mathrm{m}$ (PM10). Classroom mean concentration by centre. The line at $50 \mu \mathrm{g} \cdot \mathrm{m}^{-3}$ shows the US Environmental Protection Agency (EPA) annual standard. The line at $150 \mu \mathrm{g} \cdot \mathrm{m}^{-3}$ shows the US EPA 24-h standard. 


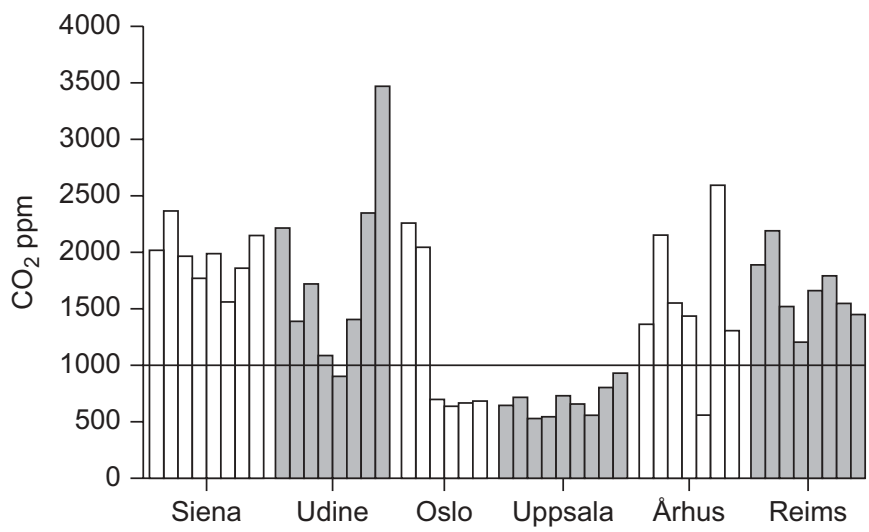

FIGURE 2. Indoor $\mathrm{CO}_{2}$. Classroom mean concentration by centre. The line at $1,000 \mathrm{ppm}$ shows the American Society of Heating, Refrigerating, and Air Conditioning Engineers standard.

In $69.6 \%$ of the classrooms (France 100\%, Italy 94\%, Denmark $86 \%$, Norway $33 \%$ and Sweden $11 \%$ ) the mean personal outdoor supply rates were lower than the minimum school level suggested by ASHRAE for occupant comfort $\left(8 \mathrm{~L} \cdot \mathrm{s}^{-1} \cdot\right.$ person $^{-1}$ ) (fig. 3) [19]. A poor ventilation rate was significantly more frequent in naturally ventilated classrooms $(67 \%)$ than in those with mechanical ventilation (97 versus $13 \%$, $p<0.001)$. The mean personal outdoor supply rate was inversely correlated with both indoor PM10 $(r=-0.71$, $\mathrm{p}<0.001)$ and $\mathrm{CO}_{2}(\mathrm{r}=-0.88, \mathrm{p}<0.001)$.

\section{Respiratory health}

In the total sample, dry cough at night (34\%) and rhinitis (32\%) were more reported than wheeze (13\%). All symptoms/ diseases were more frequent in Italy and France. The mean prevalence rate of wheeze in these two countries was $15 \%$ versus $11 \%$ in the others; corresponding values for dry cough and rhinitis were $41 \%$ versus $25 \%$, and $39 \%$ versus $26 \%$, respectively. Prevalence of rhinitis was elevated in Norway too (table 2).

In the whole sample, age did not affect respiratory health. At the country level, symptomatic children were slightly older

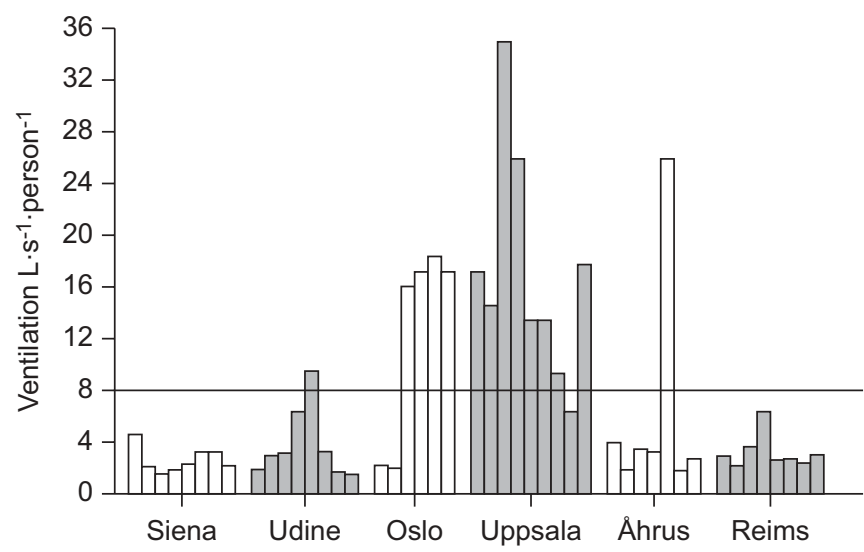

FIGURE 3. Ventilation rate. Mean personal outdoor supply rate by centre. The line at $8 \mathrm{~L} \cdot \mathrm{S}^{-1} \cdot$ person ${ }^{-1}$ shows the American Society of Heating, Refrigerating, and Air Conditioning Engineers standard.

than asymptomatic ones only for dry cough in France (9.7 versus 9.4 yrs; $\mathrm{p}=0.01)$ and rhinitis in Italy (10.0 versus $9.7 \mathrm{yrs}$; $\mathrm{p}=0.01)$.

Wheezing was more prevalent in young males than young females (16\% versus $11 \%)$, and dry cough in young females than young males ( $38 \%$ versus $31 \%$; $p=0.06)$, whereas the prevalence of rhinitis was similar in young females and young males (31\% and 33\%, respectively).

About $34 \%$ of the children were exposed to tobacco smoking at home, ranging from $17.4 \%$ in Sweden to $48.4 \%$ in France. All disorders were more frequent in exposed than unexposed children, significantly so for wheeze and dry cough (table 2). Multiple logistic regression models accounted for $\mathrm{CO}_{2}$ and PM10 exposure, sex and age showed an almost double risk for dry cough at night (OR 1.98, 95\% CI 1.34-2.91) and wheeze (OR $1.95,95 \%$ CI 1.15-3.32) in children exposed to passive smoking compared with unexposed ones.

Prevalence rates of all disorders were higher in children in classrooms with a personal outdoor air supply rate $<10 \mathrm{~L} \cdot \mathrm{s}^{-1} \cdot$ person $^{-1}(\mathrm{n}=481,74 \%)$, significantly so for dry cough

\begin{tabular}{|c|c|c|c|c|c|c|c|}
\hline \multirow[t]{2}{*}{ TABLE 2} & \multicolumn{7}{|c|}{$\begin{array}{l}\text { Prevalence (\%) of respiratory health of the studied schoolchildren, by country and passive smoking exposure at home } \\
\text { (ETS) }\end{array}$} \\
\hline & Total & Italy & Norway & Sweden & Denmark & France & $p$-value \\
\hline Subjects n & 654 & 242 & 29 & 134 & 90 & 159 & \\
\hline Wheeze & 13.3 & 13.2 & 10.3 & 11.3 & 10.1 & 17.6 & NS \\
\hline Dry cough at night & 34.4 & 47.1 & 31.0 & 17.2 & 25.8 & 35.1 & $<0.001$ \\
\hline \multirow{2}{*}{ Rhinitis } & 31.7 & 35.4 & 41.4 & 25.6 & 11.1 & 41.6 & $<0.001$ \\
\hline & ETS no & ETS yes & & & & & \\
\hline Subjects & 420 & 217 & & & & & \\
\hline Wheeze & 10.6 & 18.1 & & & & & $<0.05$ \\
\hline Dry cough at night & 28.3 & 46.0 & & & & & $<0.001$ \\
\hline Rhinitis & 30.9 & 35.3 & & & & & NS \\
\hline
\end{tabular}

Data are presented as \%, unless stated otherwise. Ns: not significant. p-values were calculated using Chi-squared test. 


\begin{tabular}{|c|c|c|c|c|c|c|}
\hline \multirow[t]{3}{*}{ TABLE 3} & recer & $\begin{array}{l}\text { atory disc } \\
\text { disorders }\end{array}$ & $\begin{array}{l}\text { rs by in } \\
\text { h expos }\end{array}$ & $\begin{array}{l}\text { or exposure level } \\
\text { e levels (reference }\end{array}$ & $\begin{array}{l}\text { particulate matter ( } P \\
\text { low level) }\end{array}$ & ) and $\mathrm{CO}_{2}$, and \\
\hline & \multirow[t]{2}{*}{ Low } & \multirow[t]{2}{*}{ Elevated $^{\#}$} & \multirow[t]{2}{*}{ p-value } & \multicolumn{2}{|c|}{$\begin{array}{l}\text { Conventional logistic } \\
\text { regression models }\end{array}$} & \multirow{2}{*}{$\begin{array}{c}\begin{array}{c}\text { Two-level" hierarchical } \\
\text { regression models }\end{array} \\
\text { Adjusted } \mathrm{OR}^{+}(95 \% \mathrm{Cl})\end{array}$} \\
\hline & & & & Crude OR (95\% Cl) & Adjusted $\mathrm{OR}^{+}(95 \% \mathrm{Cl})$ & \\
\hline \multicolumn{7}{|l|}{$\mathrm{PM}_{10} \mu \mathrm{g} \cdot \mathrm{m}^{-3}$} \\
\hline Wheeze & 11.8 & 13.8 & NS & $1.20(0.65-2.22)$ & $1.22(0.51-2.91)$ & $0.98(0.93-1.04)$ \\
\hline Dry cough at night & 20.8 & 38.6 & $<0.001$ & $2.39(1.49-3.86)^{\star \star \star}$ & $1.21(0.63-2.31)$ & $0.89(0.27-2.96)$ \\
\hline Rhinitis & 28.6 & 31.9 & NS & $1.17(0.76-1.82)$ & $0.72(0.38-1.36)$ & $0.59(0.22-1.57)$ \\
\hline \multicolumn{7}{|l|}{$\mathrm{CO}_{2} \mathrm{ppm}$} \\
\hline Wheeze & 11.9 & 13.9 & NS & $1.20(0.72-2.01)$ & $1.24(0.55-1.03)$ & $1.52(0.68-3.39)$ \\
\hline Dry cough at night & 21.0 & 40.0 & $<0.001$ & $2.52(1.69-3.76)^{\star * *}$ & $2.99(1.65-5.44)^{\star \star}$ & $3.32(1.21-9.09)^{*}$ \\
\hline
\end{tabular}

\#: PM10 $>50 \mu \mathrm{gg} \cdot \mathrm{m}^{-3}, \mathrm{CO}_{2}>1,000 \mathrm{ppm}$. ": first level, child; second level, classroom. ${ }^{+}$: analysis accounted for passive exposure to tobacco smoking at home, sex, age, PM10 (increment: $10 \mu \mathrm{g} \cdot \mathrm{m}^{-3}$ ), and $\mathrm{CO}_{2}$ (increment: $100 \mathrm{ppm}$ ). NS: not significant. *: $\mathrm{p}<0.05$; ${ }^{* *}: \mathrm{p}<0.01$; ${ }^{* *}: \mathrm{p}<0.001$. p-values were calculated using Chi-squared test.

at night and rhinitis $(40.4 \%$ versus $18.6 \%, \mathrm{p}<0.001$ and $34.6 \%$ versus $23.8 \%, \mathrm{p}<0.01$, respectively). No significant difference was evident for wheeze (14.3\% versus $10.5 \%)$.

Pupils exposed to an elevated level of indoor PM10 $(n=508$, $78 \%)$ and $\mathrm{CO}_{2}(\mathrm{n}=432,66 \%)$ showed higher prevalence of all disorders than those exposed to a low level, significantly so for dry cough at night, and, as regards $\mathrm{CO}_{2}$, also for rhinitis (table 3$)$. The prevalence of dry cough significantly $(\mathrm{p}<0.001)$ decreased with decreasing mean indoor levels of PM10 and $\mathrm{CO}_{2}$ (fig. 4).

After accounting for passive smoking at home, PM10, sex and age, the exposure to an elevated $\mathrm{CO}_{2}$ level was a significant risk factor for rhinitis and dry cough at night (table 3 ). The association with dry cough was also confirmed by the twolevel hierarchical logistic regression.

Dry cough at night and rhinitis were positively and significantly related to $\mathrm{CO}_{2}$, by both multiple conventional and twolevel logistic models, and also when PM10 and $\mathrm{CO}_{2}$ were included in the analyses as continuous variables. For $\mathrm{CO}_{2}$ the

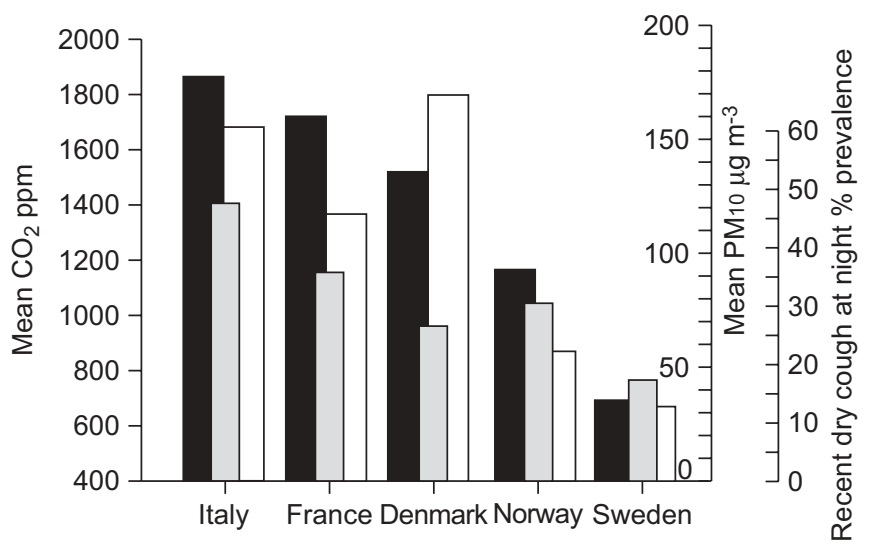

FIGURE 4. Prevalence of recent dry cough at night ( $\square$ ) according to $\mathrm{CO}_{2}(\mathbf{D})$ and particulate matter with a 50\% cut-off aerodynamic diameter of $10 \mu \mathrm{m}$ (PM10) $(\square)$ indoor mean concentrations in the different countries. risk significantly increased for an incremental increase of 100 ppm (table 4).

Neither outdoor concentrations of PM10 nor the presence of heavy vehicular traffic had an effect on the considered disorders.

Table 5 depicts the results of acoustic rhinometry. The mean anterior MCA did not significantly differ among centres. Conversely, the mean posterior MCA was significantly higher in Sweden than in Italy and France. Both anterior and posterior MCAs were significantly correlated to the inverse of PM10 and $\mathrm{CO}_{2}$ concentrations, except for the anterior area with $\mathrm{CO}_{2}$. Schoolchildren exposed to an elevated PM10 level had lower mean MCAs than those exposed to a low level ( 0.69 versus $0.76 \mathrm{~cm}^{2}, \mathrm{p}<0.05$ by ANOVA for the anterior MCA, and 0.9 versus $1.21 \mathrm{~cm}^{2}, \mathrm{p}<0.01$, for the posterior MCA). Multiple regression analyses accounted for the $\mathrm{CO}_{2}$ level, passive smoking at home, sex and age confirmed the significant inverse association of MCAs with the elevated level of PM10 $(B=-0.10, p<0.05$, for the anterior MCA; $B=-0.35, p<0.01$, for the posterior MCA). The other variables in the models did not significantly affect nasal patency.

\section{DISCUSSION}

The HESE study has found a poor IAQ in European schools in terms of $\mathrm{CO}_{2}$ and PM10 concentrations. In most school classrooms, such levels exceed the international standards for good IAQ and are related to respiratory disturbances and reduce nasal patency in children.

Current knowledge on IAQ in schools and its health effects in schoolchildren is still limited [21]. A limitation of the previous studies conducted in Europe [12, 22-24] is the use of different protocols, which precludes adequate data comparison among different countries. The HESE is a pilot study on a nonrepresentative sample of European schools. However, it provides, for the first time, data from a wide range of locations from different countries using the same standardised procedure. It shows the feasibility of multicentre studies on school 
TABLE 4 Associations of recent respiratory disorders with indoor concentrations of particulate matter (PM10) and $\mathrm{CO}_{2}$

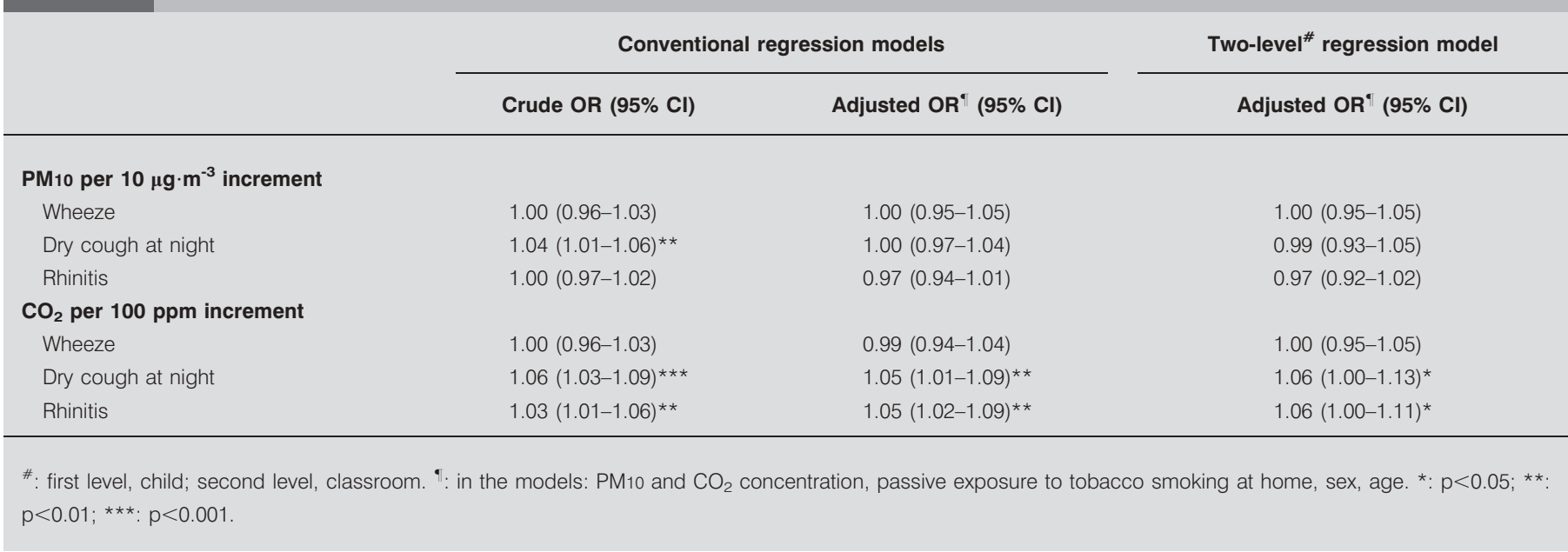

IAQ, and represents an important base for further research on a representative sample.

In the classrooms used in the HESE study, the mean personal outdoor supply rates often do not meet the minimum ASHRAE guidelines for ventilation, as observed in France [25], Poland [26] and the USA [21]. Mechanical ventilation results in higher air exchange rates than natural ventilation [27]. The latter varies according to building characteristics, occupant activities and number, and weather conditions. $\mathrm{CO}_{2}$ is a normal constituent of exhaled breath, and its levels are often used as a surrogate for ventilation rate. Even if levels $<1,000$ ppm do not always mean adequate ventilation, higher levels indicate poor ventilation, which can allow accumulation of other contaminants [21]. We found $\mathrm{CO}_{2}$ levels $<1,000 \mathrm{ppm}$ only in classrooms with mechanical ventilation (Sweden and, in part, Norway), with the exception of one classroom in Udine (900 ppm) and one classroom in Denmark (561 ppm). Even in the Shanghai study [28], natural ventilation was not enough to reduce $\mathrm{CO}_{2}$ to normal levels: opening one section window reduced mean indoor $\mathrm{CO}_{2}$ by only $90 \mathrm{ppm}$. Likewise, in naturally ventilated Polish schools, $\mathrm{CO}_{2}$ was always $>1,000$ ppm [26], as also found in a US study [29].
Moreover, indoor PM10 exceeded the standard of $50 \mu \mathrm{g} \cdot \mathrm{m}^{-3}$ in about $78 \%$ of the HESE classrooms. Even if outdoor and indoor levels were positively correlated (Pearson $r=0.52, p<0.001$ ), indoor variability accounted for only $27 \%$ of the linear association with outdoor PM10. In all centres, PM10 concentration was lower outside the school, thus suggesting indoor PM10 was mainly produced by indoor sources. This was also indicated by a study in the Czech Republic, which, after comparing particles with different diameters, showed that an important portion of indoor PM10 had its source inside the classroom [30].

Few studies have investigated the relationships between symptoms in children and $\mathrm{CO}_{2}$ concentrations at school. In Norway, $\mathrm{CO}_{2}$ levels were significantly related to a higher prevalence of symptoms of upper airway irritation [31]. Dutch children complained more of building-related symptoms when exposed to higher indoor $\mathrm{CO}_{2}$ concentrations at school [32]. In the USA, school attendance significantly decreased with increasing $\mathrm{CO}_{2}$ in the classrooms [33]. HESE children exposed to an elevated level of $\mathrm{CO}_{2}$ showed significantly higher occurrence of dry cough at night and rhinitis, even after accounting for confounders. Significant positive associations of

TABLE 5 Rhinometry: minimum cross-sectional areas (MCAs) in the total sample and by centre

\begin{tabular}{|c|c|c|c|c|c|c|}
\hline & Total & Italy & Sweden & Denmark & France & $p$-value \\
\hline \multicolumn{7}{|l|}{ Anterior MCA } \\
\hline Mean $\mathrm{cm}^{2}$ & 0.70 & 0.72 & 0.74 & 0.66 & 0.70 & NS \\
\hline $95 \% \mathrm{Cl} \mathrm{cm}^{2}$ & $(0.68-0.73)$ & $(0.67-0.76)$ & $(0.70-0.79)$ & $(0.63-0.70)$ & $(0.64-0.75)$ & \\
\hline Median $\mathrm{cm}^{2}$ & 0.69 & 0.72 & 0.71 & 0.67 & 0.70 & \\
\hline Mean $\mathrm{cm}^{2}$ & 1.03 & 1.02 & 1.16 & & 0.83 & $<0.01$ \\
\hline $95 \% \mathrm{Cl} \mathrm{cm}^{2}$ & $(0.97-1.10)$ & $(0.92-1.11)$ & $(1.05-1.28)$ & & $(0.74-0.92)$ & \\
\hline Median $\mathrm{cm}^{2}$ & 0.97 & 0.94 & 1.10 & & 0.85 & \\
\hline
\end{tabular}

NS: not significant. p-values were measured using ANOVA. 
dry cough at night and rhinitis were found also with a small increment $(100 \mathrm{ppm})$ in $\mathrm{CO}_{2}$ concentration. As regards its skewed distribution, $\mathrm{CO}_{2}$ was additionally analysed as a categorical variable based on its quartile distribution, and significant trends to augment odd ratios with increase in exposure were found for both dry cough and rhinitis (data not shown). It is important to point out that the results did not substantially change when the multilevel hierarchical models were fitted.

There is evidence that indoor particulate matter significantly affects children's respiratory health. In Swedish schoolchildren, associations between respirable dust concentrations or the amount of settled dust in the classroom and asthma symptoms, new onset of self-reported pet allergy and new onset of asthma diagnoses have been reported [12, 22]. We found a strong crude association between the elevated level of PM10 and the presence of dry cough at night (OR 2.39, 95\% CI 1.49-3.86), but it was probably due to the confounding effect of $\mathrm{CO}_{2}$ exposure. In fact, the association was still significant after accounting for sex, age and passive smoking (OR 1.99, 95\% CI 1.15-3.18), whereas it was no longer significant when $\mathrm{CO}_{2}$ concentration (increment: $100 \mathrm{ppm}$ ) was included in the model (OR 1.21, 95\% CI 0.63-2.31).

In the HESE study, PM10 was associated with lower MCAs, as measured by acoustic rhinometry. MCAs indicate the degree of openness of the nose, regulate airflow and correlate with symptoms of nasal obstruction [16]. Our results partly agree with NORBäCK et al. [13] who found a lower degree of nasal patency among school staff exposed to higher concentrations of respirable dust in schools. A study conducted by WÅLINDER et al. [34] showed that better cleaning will increase nasal patency.

It seems that parents tend to report fewer symptoms than their children do, and that children 10-11 yrs old provide important independent information, especially on their nocturnal symptoms (e.g. dry cough) [35]. By comparing reports from children and parents, we also observed a different perception of symptoms. Children reported all disorders at higher frequency than their parents did. Except for wheezing, which showed quite good concordance (Cohen's kappa 0.60, 90\% of absolute agreement), both dry cough at night and rhinitis had a poor concordance $(0.30,70 \%)$. By including information from both children and parents in the same data set, we might have overor underestimated symptoms/diseases. However, sensitivity analyses, stratified by information source, showed significant positive associations of $\mathrm{CO}_{2}$ exposure with dry cough at night, independently of whether the information was taken from children or parents. The association with rhinitis was significant when the reports from children were considered, and the association was evident, but not significant, when we derived information from parents only (data not shown).

\section{Conclusions}

The HESE study shows levels of $\mathrm{CO}_{2}$ and PM10 exceeding the suggested air quality standards in a large number of European classrooms. Exposure to elevated levels affects the respiratory health of schoolchildren. Such results foster the advocacy for improving school environments, initially by providing adequate ventilation.
Future research is needed to assess the indoor environment in a larger sample of schools and the long-term health effects. An extension of the HESE study design to other member states of the EU would be worthwhile.

\section{SUPPORT STATEMENT}

This study was supported by the European Commission, Directorate General for Health and Consumer Affairs (DG SANCO, Luxembourg, Luxembourg), contract SPC.2002391.

\section{STATEMENT OF INTEREST}

None declared.

\section{ACKNOWLEDGEMENTS}

The authors would like to thank the schoolchildren, parents and school authorities of the participating countries.

\section{REFERENCES}

1 Rojas-Bracho L, Suh HH, Koutrakis P. Relationship among personal, indoor, and outdoor fine and coarse particle concentrations for individuals with COPD. J Expo Anal Environ Epidemiol 2000; 10: 294-306.

2 Samet JM, Spengler JD. Indoor environments and health: moving into the 21st century. AJPH 2003; 93: 1489-1493.

3 Viegi G, Annesi-Maesano I. Lung diseases induced by indoor and outdoor pollutants. In: Mapp CE, ed. Occupational Lung Disorders. Eur Respir Mon 1999; 4: 214-241.

4 Brunekreef B. Indoor environment. In: Annesi-Maesano I, Gulsvik A, Viegi G, eds. Respiratory Epidemiology in Europe. Eur Respir Mon 2000; 5: 384-399.

5 Simoni M, Scognamiglio A, Carrozzi L, et al. Indoor exposures and acute respiratory effects in two general population samples from a rural and an urban area in Italy. J Exp Anal Environ Epidemiol 2004; 14: 144s-152s.

6 Neas LM, Dockery DW, Ware JH, et al. Concentration of indoor particulate matter as a determinant of respiratory health in children. Am J Epidemiol 1994; 139: 1088-1099.

7 Viegi G, Simoni M, Scognamiglio A, et al. Indoor air pollution and airway disease. Int J Tuberc Lung Dis 2004; 8: 1401-1415.

8 Moglia D, Smith A, MacIntosh DL, et al. Prevalence and implementation of IAQ programs in U.S. schools. Environ Health Perspect 2006; 114: 141-146.

9 Blondeau P, Iordache V, Poupard O, et al. Relationship between outdoor and indoor air quality in eight French schools. Indoor Air 2005; 15: 2-12.

10 Synnott H, Hanley O, Fenton D, et al. Radon in Irish schools: the results of a national survey. J Radiol Protect 2006; 26: $85-96$.

11 Instanes C, Hetland G, Berntsen S, et al. Allergens and endotoxin in settled dust from day-care centres and schools in Oslo, Norway. Indoor Air 2005; 15: 356-362.

12 Smedje G, Norback D. Irritants and allergens at school in relation to furnishings and cleaning. Indoor Air 2001; 11: 127-133.

13 Norbäck D, Walinder R, Wieslander G, et al. Indoor air pollutants in schools: nasal patency and biomarkers in nasal lavage. Allergy 2000; 55: 163-170.

14 Carrer P, Bruinen de Bruin Y, Franchi M, et al. The EFA Project: indoor air quality in European schools. In: Levin $\mathrm{H}$, ed. Proceedings from the International Conference on Indoor Air Quality and Climate, 30 June to 5 July 2002, Monterey, California. Monterey, ISIAQ Publications, 2002; pp. 794-799.

15 Norbäck D, Ancker K, Johanson G. Field evaluation of $\mathrm{CO}_{2}$ detector tubes for measuring outdoor air supply rate in the indoor environment. Indoor Air 1992; 2: 58-64. 
16 Norbäck D, Wieslander G. Biomarkers and chemiosensory irritation. Int Arch Occup Environ Health 2002; 75: 298-304.

17 US EPA Office of Air and Radiation. EPA's Revised Particulate Matter Standards. Fact Sheet. Washington, Office of Air Quality Planning and Standards, 1997.

18 ASHRAE Handbook. HVAC Systems and Equipment. Atlanta, American Society of Heating, Refrigerating, and Air Conditioning Engineers, 1996.

19 ASHRAE. Ventilation for Acceptable Indoor Air Quality, Standard 62-1999. Atlanta, American Society for Heating, Refrigerating and Air conditioning Engineers, 1999.

20 Seppänen OA, Fisk WJ. Summary of human responses to ventilation. Indoor Air 2004; 14: Suppl. 7, 102-118.

21 Daisey JM, Angell WJ, Apte MG. Indoor air quality, ventilation and health symptoms in schools: an analysis of existing information. Indoor Air 2003; 13: 53-64.

22 Smedje G, Norbäck D, Edling C. Asthma among secondary school pupils in relation to the school environment. Clin Exp Allergy 1997; 27: $1270-1278$.

23 Meklin T, Husman T, Vepsalainen A, et al. Indoor air microbes and respiratory symptoms of children in moisture damaged and reference schools. Indoor Air 2002; 12: 175-183.

24 Almqvist C, Larsson PH, Egmar AC, et al. School as a risk environment for children allergic to cats and a site for transfer of cat allergen to homes. J Allergy Clin Immunol 1999; 103: 1012-1017.

25 Riberon J, O'Kelly P, Maupetit F, et al. Indoor air quality in schools: the impact of ventilation conditions and indoor activities. In: Levin $\mathrm{H}$, ed. Proceedings from the International Conference on Indoor Air Quality and Climate, 30 June to 5 July 2002, Monterey, California, Vol. 2. Monterey, ISIAQ Publications, 2002; pp. 109-114.

26 Sowa J. Air quality and ventilation rates in schools in Poland requirements, reality, and possible improvements. In: Levin $\mathrm{H}$, ed. Proceedings from the International Conference on Indoor Air Quality and Climate, 30 June to 5 July 2002, Monterey, California, Vol. 2. Monterey, ISIAQ Publications, 2002; pp. 68-73.
27 Scheff PA, Paulius VK, Huang SW, et al. Indoor air quality in a middle school, part I: use of $\mathrm{CO}_{2}$ as a tracer for effective ventilation. Appl Occup Environ Hyg 2000; 15: 824-834.

28 Mi Y-H, Norbäck D, Tao J, et al. Current asthma and respiratory symptoms among pupils in Shanghai, China: Influence of building ventilation, nitrogen dioxide, ozone, and formaldehyde in the classrooms. Indoor Air 2006; 16: 454-464.

29 Fox A, Harley W, Feigley C, et al. Increased levels of bacterial markers and $\mathrm{CO}_{2}$ in occupied school rooms. J Environ Monit 2003; 5: 246-252.

30 Branis M, Rezacova P, Domasova M. The effect of outdoor air and indoor human activity on mass concentrations of PM10, PM2.5, and PM1 in a classroom. Environ Res 2005; 99: 143-149.

31 Myhrvold AN, Olsen E, Lauridsen O. Indoor environment in schools - pupils' health and performance in regard to $\mathrm{CO}_{2}$ concentrations. In: Yoshizawa $\mathrm{S}$ et al., eds. Proceedings from the International Conference on Indoor Air Quality and Climate, 2128 July 1996, Nagoya, Japan, Vol. 4. Nagoya, ISIAQ Publications, 1996; pp. 369-374.

32 Potting J, van de Sandt P, ter Haar Romeny-Wacher I, et al. Health complaints, $\mathrm{CO}_{2}$ levels and indoor climate in Dutch schools. In: Seifert B, ed. Proceedings from the International Conference of Indoor Air Quality and Climate, 17-21 August 1987, West Berlin, Germany, Vol. 3. Berlin, Institute for Water, Soil and Air Hygiene, 1987; pp. 582-586.

33 Shendell DG, Prill R, Fisk WJ, et al. Associations between classroom $\mathrm{CO}_{2}$ concentrations and student attendance in Washington and Idaho. Indoor Air 2004; 14: 333-341.

34 Wålinder R, Norbäck D, Wieslander G, et al. Nasal patency and lavage biomarkers in relation to settled dust and cleaning routines in schools. Scand J Work Environ Health 1999; 25: 137-143.

35 Hoek G, Wypij D, Brunekreef B. Self-reporting versus parental reporting of acute respiratory symptoms of children and their relation to pulmonary function and air pollution. Int J Epidemiol 1999; 28: 293-299. 